\title{
Customer preferences versus managerial decision-making in open innovation communities: the case of Starbucks
}

\author{
María del Rocío Martínez-Torres ${ }^{\mathrm{a} *}$ @, , F. Rodriguez-Piñero ${ }^{\mathrm{a}}$ and Sergio L. Toral ${ }^{\mathrm{b}}$ \\ ${ }^{a}$ Facultad de Turismo y Finanzas, University of Seville, Avda. San Francisco Javier s/n, Seville 41018, Spain; \\ ${ }^{b}$ E. S. Ingenieros, University of Seville, Avda. Camino de los Descubrimientos s/n, Seville 41092, Spain
}

\begin{abstract}
Customers can participate in open innovation communities posting innovation ideas, which in turn can receive comments and votes from the rest of the community, highlighting user preferences. However, the final decision about implementing innovations corresponds to the company. This paper is focused on the customers' activity in open innovation communities. The aim is to identify the main topics of customers' interests in order to compare these topics with managerial decision-making. The results obtained reveal first that both votes and comments can be used to predict user preferences; and second, that customers tend to promote those innovations by reporting more comfort and benefits. In contrast, managerial decisions are more focused on the distinctive features associated with the brand image.
\end{abstract}

Keywords: open innovation; innovation policies; customer communities; collective intelligence; decision-making

\section{Introduction}

Organisations have widely acknowledged the role of innovations in economic growth. Technological developments have forced higher competitiveness and shorter innovation cycles and, as a result, companies increase their efforts in innovation activities (Hekkert and Negro 2009). As a further step, companies have begun to open their innovation processes by incorporating both internal and external resources, leading to the so-called open innovation paradigm (Chresbrough 2003). Open Innovation is a recent strategy related to the management of information in organisations, and relies on the idea that potential opportunities and advantages can be gained outside the formal boundaries of organisations (Huizingh 2011; Martinez-Torres 2013; Holzmann, Sailer, and Galbraith 2014). This is especially important in companies offering daily-use products, which require a constantly updated external feedback to measure its progress and development.

This paper is focused on a representative example of this kind of organisation: Starbucks. The distinctive element of this company with respect to the competitors is to offer its clients a quality service at all levels. In this line, Starbucks CEO and chairman, Howard Schultz, determines

*Corresponding author. Email: rmtorres@us.es 
the necessity to renovate the company's image by retracing the company's steps in the same direction it did from its origin: orienting it to giving personalised attention to each customer. Starbucks, like most companies, is aware of the importance of the new technologies and the diffusion of the Internet as a tool that can be reached by many customers (Sigala 2012). The open innovation website is actually a fundamental element in the strategy of restructuring. Through the 'My Starbucks Idea' website, not only users can post and share ideas with the rest of users, but comment and vote other previously posted ideas. These two last forms of participation, commenting and voting, allow users to exert some pressure on the organisation highlighting their preferences. However, the organisation receives thousands of ideas and must individually asses each one. Moreover, not all the posted ideas, even if they are quite popular, can be implemented by the organisation since they can be prohibitive due to its high cost or they can be in conflict with the image and the mission of the organisation.

This paper investigates customers' preferences and Starbucks decision-making when adopting ideas. More specifically, the paper tries to test to what extent the preferences of customers are influencing the adoption of ideas. Although this research is restricted to the case study of My Starbucks Idea, which is a well-known open innovation platform, the proposed methodology can be easily extended to other similar consumer platforms.

The main contribution of this research is the analysis of open innovation communities from the double perspective of the customers and the company, which can explain some biases in the innovation policy of companies or to what extent customers can influence future innovations. The remainder of the paper is structured as follows: the next section explains the concept of open innovation and its implementation through open innovation communities. Section 3 proposes the hypotheses of this study. Section 4 details the methodology for extracting the data from the 'My Starbucks Idea' website and the variables considered. Section 5 shows the results obtained that are next discussed in Section 6. Finally Section 7 concludes the paper.

\section{Literature review}

The term open innovation was coined by Prof. Chesbrough (2003) and refers to the use of purposive inflows and outflows of knowledge to accelerate internal innovation, and expand the markets for external use of innovation, respectively. This paradigm assumes that firms can use external ideas and internal ideas, as well as internal and external paths to market in order to advance their technology. In contrast to the traditional innovation model, this paradigm also assumes that the risks derived from opening the innovation, such as the access to valuable information by competitors or the loss of control over the innovation process, can be compensated by a richer number of innovative ideas.

Several classifications have been proposed in the literature about open innovation. Toral, Martinez-Torres, and Di Gangi (2011) distinguish between product and process innovations. According to the degree of openness in innovation, open innovation strategies can also be classified as outsourcing, crowdsourcing and online contests (Huff, Moslein, and Reichwald 2013). Online contests are intended as competitions among users in order to reach the best idea/proposal and the winner is rewarded (Harland and Nienaber 2014). However, the generation of ideas through a website can be considered as a form of crowdsourcing, which is not intended as a competition (Martinez-Torres 2014a). They have been popularised, thanks to the emergence of Web 2.0 (Bayus 2013). Firms such as Microsoft, Dell, IBM, BMW and Nokia increasingly invest in virtual communities to solicit user contributions as part of their innovation processes. This trend 
is explained by the increase in digitalisation and the decrease in the costs of communication that have led to an exponential growth of user innovation platforms (Mahr and Lievens 2012).

However, some major unresolved issues regarding open innovation still remain open. One of them refers to the selection of the best stage in which open innovation can be more effective. In the case of new service development processes, user involvement is often more intense at the initial stages of idea generation and screening, and again at the later stages of test marketing and commercialisation. Several studies conclude that it is better involving customers at the earliest stages as they can provide later substantial reductions in time, costs and corrections (Cooper and Kleinschmidt 1994; Alam 2006). Another important question refers to managerial decisionmaking. Gassmann, Enkel, and Chesbrough (2010) argue that the internal process by which companies manage open innovation is still more trial and error than a professionally managed process. Open innovation can be seen as a support for managerial decision-making, problem solving and opportunity exploiting (Chiu, Liang, and Turban 2014). The collective evaluation system of ideas typically implemented by open innovation communities allows to distinguish customer preferences, and also reveals mismatching between customer preferences and companies' decision-making (Martinez-Torres 2014a). This study goes further in this analysis by first considering the main topics chosen by customers, and then comparing them with the final company decision-making. In contrast to previous papers in this topic that use a qualitative approach (Sigala 2012), this paper proposes a quantitative approach. Thousands of ideas must be collected and analysed to obtain the categories or topics they belong to. Although data are publicly available, not all the information contained in web pages is useful and meaningful, and data have to be automatically extracted for each one of the thousands of posted innovations. These data extraction methods can be framed within the Big Data methodologies, which represent an emergent trend within social sciences (Arenas-Marquez, Martinez-Torres, and Toral 2014; Chang, Kauffman, and Kwon 2014; Martinez-Torres 2014b).

\section{Hypotheses}

The two primary forms of participation in online communities consist of commenting and voting. Previous works support that both forms of participation tend to be correlated. For instance, this is the case of Dell Ideas Storm, the open innovation community from Dell, where comments, promotions (positive scores) and demotions (negative scores) have been proved to be correlated (Martinez-Torres 2014a). Obviously, it is cognitively more complex posting a comment than posting a score, where no justification is required. However, Bajic and Lyons (2011) proposed that collaborative websites allow users to find suggestions similar to their own, hence resulting in more votes and comments per suggestion. Both votes and comments have also been used in open innovation contests as a measure to determine users' design preferences and pre-select the most promising designs for the jury (Füller et al. 2010). Dahlander and Piezunka (2014) obtained a positive relationship between the number of suggestions from external contributors and proactive attention. Other authors have studied how the cognitive and affective feelings influence the evaluation of contributions. Readers of a message will respond to the assertiveness infused into the message as well as to the message itself, and the manner in which the message is presented. Consequently, when messages communicate negative feeling, they are likely to attract negative reactions from the community in terms of votes and comments (Kim and Miranda 2011).

Although votes and comments are publicly available, there are only few examples of studies that have explored customer-generated content in new service development. Li et al. (2010) proposed a news recommendation system based on user comments under the assumption that 
topic evolution in social media can be reflected by the comments. Therefore, votes and comments can be used as the variables to collect user preferences. Alam (2002) argues that a large number of powerful new service ideas need to be generated with user contacts and interactions, and customer participation is important for designing distinguishable and unique services. However, customers are able to suggest new services which provide them with values and solutions to their daily problems (Sigala 2012). It is widely held that service quality is perceived by customers through a comparison between service-related expectations and experiences (Grönroos 2000). These experiences are always relative to what customers consider reasonable based on their prior experiences, service provider's communications, and their own needs and aspirations in a particular situation (Kuusisto 2008). According to Vargo and Lusch's (2004), services provide customers with value only when they are used. Customer value is hence tied to a customer's meaning attached to the experience with a service. This implies that most customers' proposed innovations are biased by their previous experience, and they are mainly guided by their own needs. According to this, we propose the following hypothesis:

H1: Users' preferences tend to focus on the core activity of the company and on those ideas that report more comfort and benefits.

Crowdsourcing has been stated as a source of support for managerial decision-making (Brabham 2013), and open innovation is actually one form of crowdsourcing (Chiu, Liang, and Turban 2014). However, human biases can affect the idea generation process (Bonabeau 2009). For instance and in the case of the hospitality services, social interference or the consumers' desire for finding a solution fitting their specific needs can lead to ideas far away from the company's expectations (Sigala 2012). In some cases, the company's expectations are also drifted by the resistance to change, for instance, selling what we make rather than responding to customers' requirements. Online marketing managers often base their decisions on simple heuristics, combined with personal expertise. Personal preferences are still prevalent despite the volume of data available (Anderl et al. 2013). In the case of hospitality companies, the experience states that they can increase their market share and growth rates by increasing their brand loyal customers (Tepeci 1999). This is because the hospitality business is a mature industry where it is cheaper to serve current customers rather than acquiring new customers through advertising, promotion and start-up operating expenses. There are several studies that show the positive relationship between the brand image and customers' perceived value and purchase behaviour (Cretu and Brodie 2007; Wu 2008). Thus, we propose the following hypothesis:

$\mathrm{H} 2$ : Managerial decision-making tend to focus on the distinctive features associated with the brand image.

\section{Methodology}

This study follows a grounded theory approach, which is a general methodology for developing theory that is grounded in data systematically gathered and analysed (Strauss and Corbin 1998; Toral, Martínez-Torres, and Barrero 2009). This methodology has been used as a marketing research methodology for studying customer involvement in new service developments (Sigala 2012) or for analysing the publicly available information in online communities (Kozinets 2002). The first step to apply this methodology consists of finding an online community appropriate for 
Table 1. Categories and subcategories of posted ideas.

\begin{tabular}{ll}
\hline Product ideas & Coffee \& Espresso Drinks \\
& Frappuccino \& Beverages \\
& Tea \& other drinks \\
& Food \\
& Merchandise \& Music \\
& Starbucks Card \\
& New Technology \\
& Other Product Ideas \\
Experience ideas & Ordering or Payment \& Pick-Up \\
& Atmosphere \& Locations \\
& Other Experience Ideas \\
Involvement ideas & Building Community \\
& Social Responsibility \\
& Other Involvement Ideas \\
& Outside USA \\
\hline
\end{tabular}

the research aims. This is the case of My Starbucks Idea, which is an open innovation website where users can score and comment innovations, and where the company makes public and visible those ideas finally adopted. The second step consists of data collection. Starbucks' open innovation website identifies members' contributions as ideas. When posting an idea, registered users have to choose one of the 15 subcategories that respond to three basic aspects of the company: product, experience and involvement ideas (Table 1).

Once an idea is submitted and shared, community users can vote and comment posted ideas. Commenting an idea means that the users attach comments below the posted idea in the form of a thread of discussion. In general, comments can support, criticise or refine the idea shared and, as a result, a debate among users can emerge through these comments. Even the original author of the idea can participate answering some questions. Voting an idea consists of adding or subtracting 10 points to its current score. As long as ideas receive more votes, they are promoted to top positions in terms of popularity within the web. There is a separate category, called Ideas in Action, which shows those ideas that either have already been launched (adopted by the company) or that are currently coming soon. Therefore, this category includes those ideas that have been considered by Starbucks for their implementation.

Three variables have been considered in this study: votes, which refers to the current score of each idea; comments, defined as the number of received comments by each idea shared; and size, which refers to the number of characters of the ideas shared. The three variables have been extracted using our own crawler. A crawler is a computer program that follows the hyperlink structure of the web. In this case, the crawler is used to collect data from a specific website (Youtie et al. 2012). As the source code of each website has a different structure and style, there is no standard way of browsing through them. As a consequence, it is necessary to program a hand-made crawler. In this paper, the crawler was programmed in $\mathrm{R}$, which is a free software environment for statistical computing. The base package of $\mathrm{R}$ contains the function readLines(), which reads data from a URL. This function was used to access the shared reviews. However, webpages are formatted in HTML code, and accessed data contain both the webpage content and the HTML tags. Therefore, it is necessary to parse the HTML file using the htmlParse() function. This function generates an R structure representing the HTML tree. Once online webpages are available as an $\mathrm{R}$ structure, meaningful data can be easily identified using regular expressions 
that are also supported in R, for instance, in packages such as XML. As a result, a total of 99,528 ideas distributed over the 15 categories of Table 1 were collected. Additionally, the category of Ideas in Action was also crawled. In this case, the number of ideas is 897 . For each one of them, the number of comments received and its size were captured (the number of votes is not available in this case), as well as the categories under which these ideas were classified by Starbucks. Once data are collected, the paper first analyses the activity of users in open innovation communities in the different categories where they can post innovations. The results obtained are then compared with those ideas actually implemented by the company.

\section{Results}

A correlation analysis among the three extracted variables for the 15 categories of ideas has been performed. Results obtained in Table 2 show that participation through voting and commenting is positively correlated, while the size of ideas shared is not correlated with the other two variables.

This result suggests that those ideas that receive a higher number of votes are also generating a debate around them. Therefore, both votes and comments can be considered relevant information to identify users' preferences. However, the size of ideas is not relevant for identifying good ideas.

The distribution of the 3 variables considered over the 15 categories of ideas has been first analysed. Figure 1 illustrates the mean value and confidence intervals of the variable votes in each of the 15 categories of ideas. This figure highlights that the categories Starbucks Cards, Ordering, Payment \& Pick up and Coffee \& Espresso Drinks are the three ones that receive more votes, while New Technology is clearly the worst evaluated category by users. These results suggest that Starbucks customers are more biased towards the core activity of Starbucks, which are basically coffee and the ordering processes. Starbucks Card refers to the loyalty program of the company and its associated advantages. Taking into account that the Starbucks Card is the rewarding system to the loyalty of users and the fact that the majority of the ideas provided by the community in this category demands extending its owner's benefits, there is an obvious tendency among My Starbucks Idea members to support and vote these ideas, as stated in hypothesis H1.

Figure 2 details the mean value and confidence intervals of the variable size. In this case, three categories (Frapuccino, New Technology and Outside USA) show the highest values. The rest of them are more or less similar in size. This result can be explained because these particular categories have a wider scope, and consequently ideas need to be more precise and require longer explanations.

Finally, Figure 3 shows the mean value and the confidence intervals of the variable comments. The most popular categories in this case are Coffee \& Espresso Drinks, Frapuccino and New Technology. It is interesting to notice that Coffee \& Espresso Drinks occupies a relevant position in both votes and comments. This could be because coffee is the main product of Starbucks, and

Table 2. Correlation among variables.

\begin{tabular}{lccc}
\hline & Votes & Size & Comments \\
\hline Votes & 1000 & $-.027^{* *}$ & $.487^{* *}$ \\
Size & $-.027^{* *}$ & 1000 & $.101^{* *}$ \\
Comments & $.487^{* *}$ & $.101^{* *}$ & 1000 \\
\hline
\end{tabular}

**Correlation is significant at the .01 level (two-tailed). 


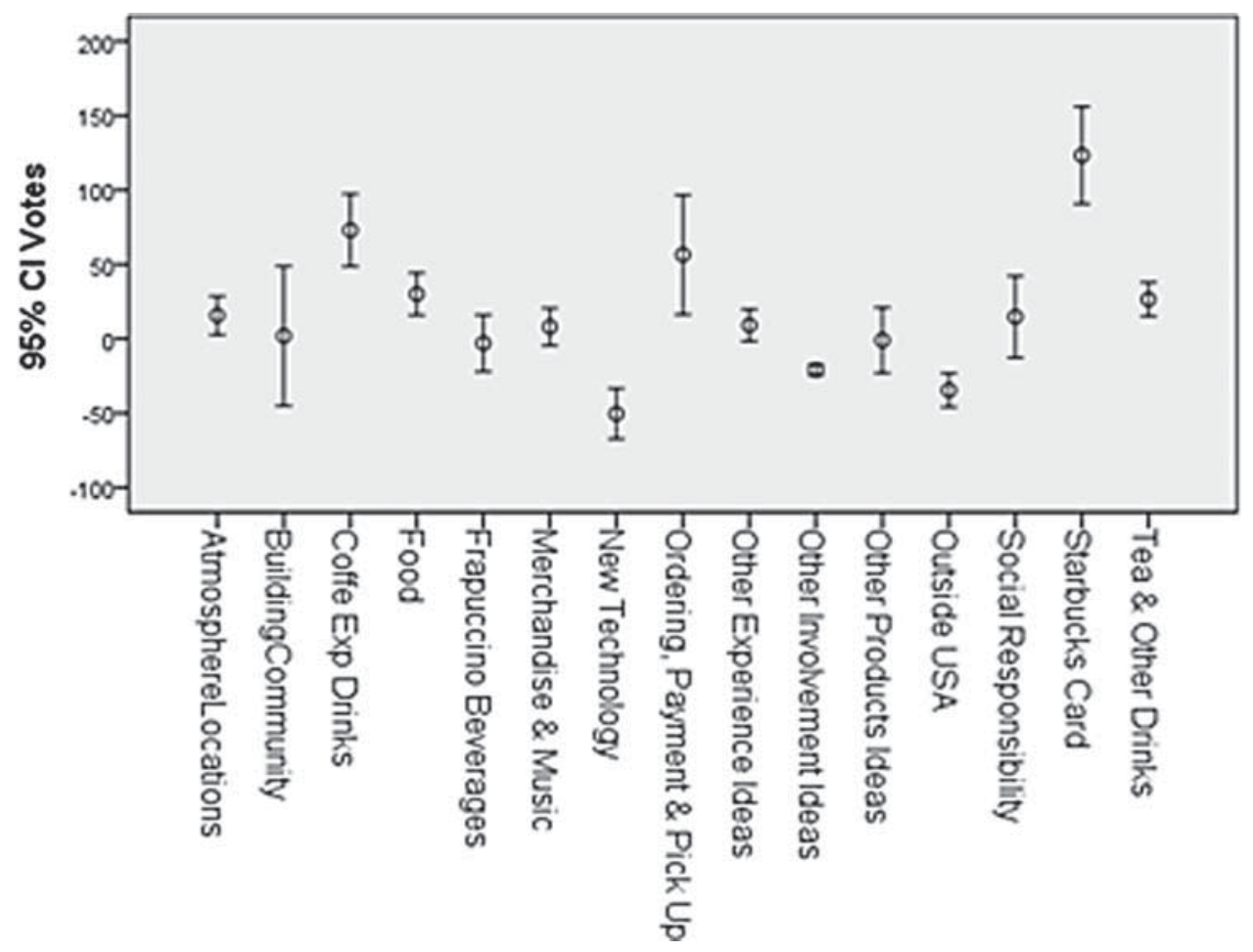

Figure 1. Mean value and confidence intervals of Votes.

people tend to associate the image brand with coffee. Therefore, this is perhaps the main category in which users are more involved in. It is also interesting to see that New Technology is in general the worst evaluated/scored category, although it arouses an important debate among users. This point can be explained by the specificity of contributions related to this category. In contrast, the debate in the categories Outside USA, Food and Merchandise \& Music is noticeably lower.

A Kruskal-Wallis test has been performed to test the equality of means of the three variables considered in each of the 15 categories of ideas. The Kruskal-Wallis test is a nonparametric version of one-way analysis of variance. The assumption behind this test is that the measurements come from a continuous distribution, but not necessarily a normal distribution. The test is based on an analysis of variance using the ranks of the data values, not the data values themselves. The low $p$-value in Table 3 for each variable suggests that the null hypothesis can be rejected, so it can be concluded that the obtained mean values in Figures 1-3 are significantly different.

Any of the previous ideas belonging to the 15 categories have the opportunity of becoming a reality. If the contribution is viable and it is considered interesting by Starbuck's quality team support, it can reach the Idea in Action status. This category actually represents the managerial decision-making, as ideas reach this status after being evaluated by the innovation department or some experts of the company. Although the final decision about ideas can be influenced by the community evaluation, it is actually an independent and autonomous decision of the company.

Figure 4 shows the distribution of the number of Ideas in Action per category of Ideas. Coffee \& Espresso Drinks, with 190 ideas in Action, is clearly the category in which more ideas have 


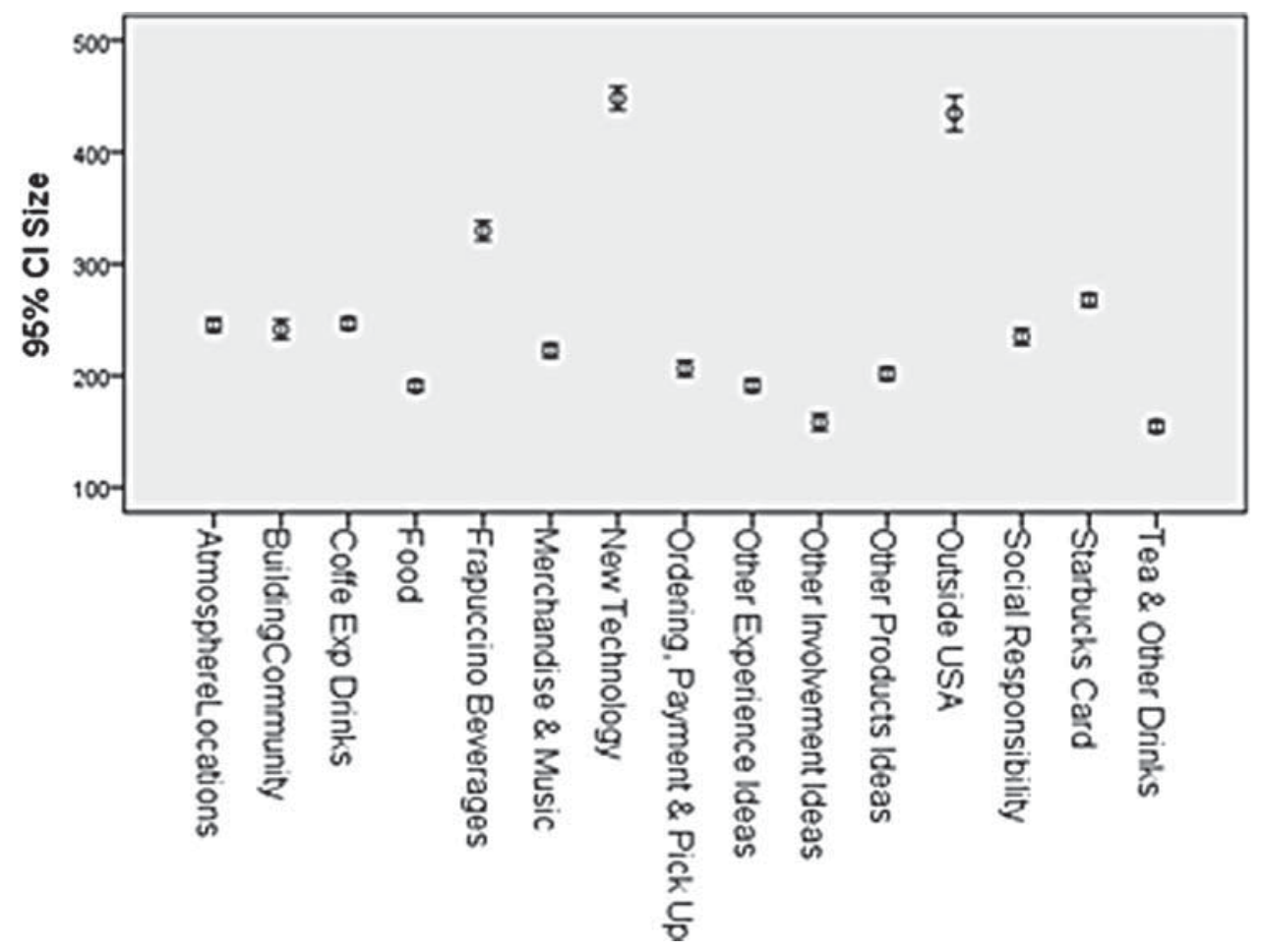

Figure 2. Mean value and confidence intervals of Size.

been selected by Starbucks. Again, this result is in line with the main product offered by the company, which is also the most closely associated with the brand image. The second and third places correspond to Other Experience Ideas and Social Responsibility.

Other Experience Ideas category provides space for those comments not instinctively classifiable in the other categories, such as partners (workers, baristas), other types of rewarding loyalty or decoration changes. This category includes the feeling of users about Starbucks, and this is an issue prioritised by the company, which considers the experience of taking a coffee in Starbucks as a distinctive experience. The same can be said about social responsibility. Starbucks aims to be an environmental-friendly green brand, concerned about social problems both in the whole world and in every single neighbourhood. The three most adopted categories are those more closely related to the brand image of the company, as hypothesised in $\mathrm{H} 2$.

\section{Discussion and implications}

Although there are several methods for importing external ideas through the scheme of open innovation, this study is specifically focused on open innovation web communities, which have gained popularity with the emergence of user-generated content (Martinez-Torres 2015).

Results obtained show there is a gap between customer preferences and managerial decisionmaking in open innovation communities. This gap can be explained because companies involved in open innovation are not still completely confident about the open innovation results. However, this is precisely contrary to what the literature has established in the sense that users are 


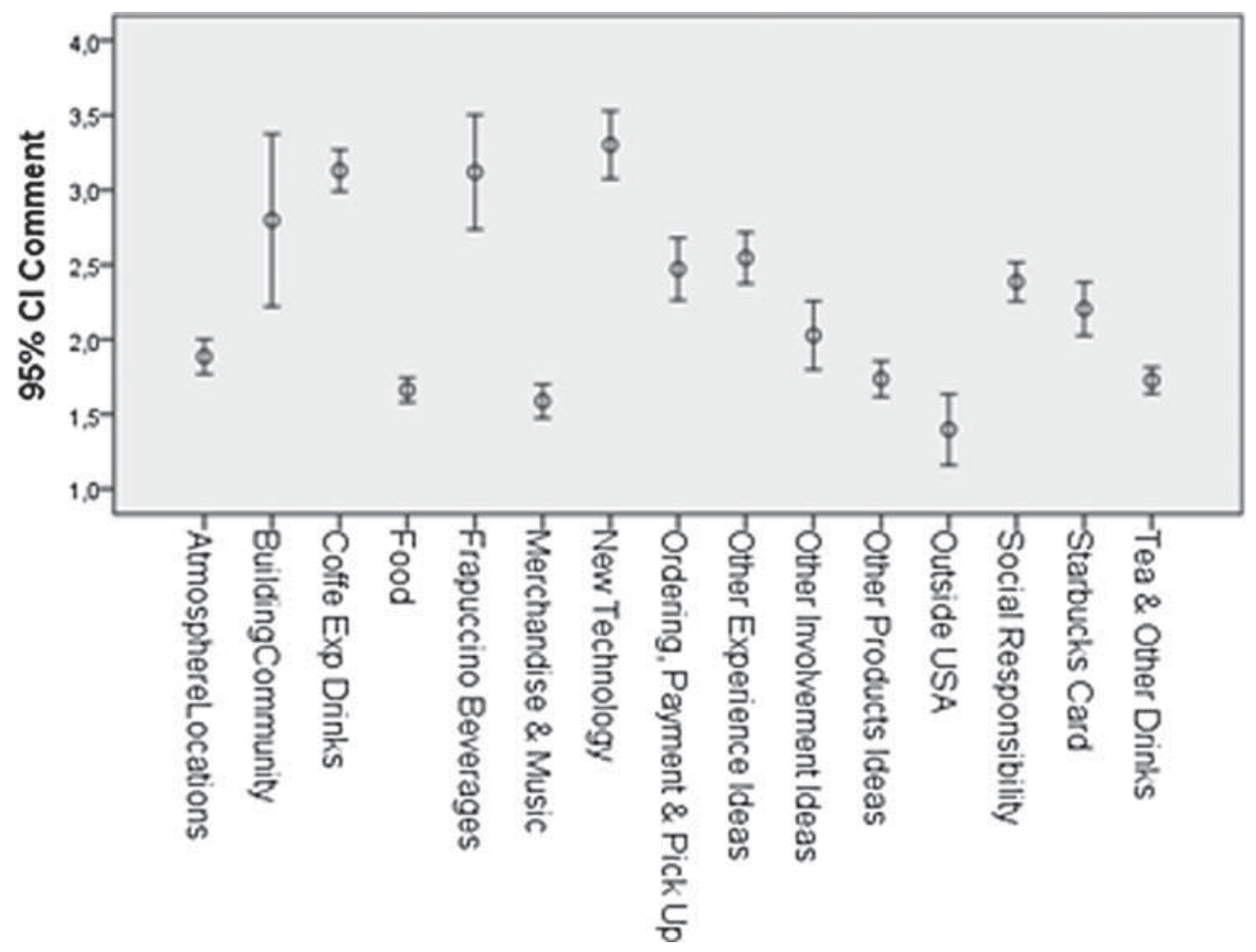

Figure 3. Mean value and confidence intervals of Comment.

Table 3. Kruskal-Wallis test.

\begin{tabular}{lccc}
\hline & Votes & Size & Comments \\
\hline Chi-square & 4713.32 & 6046.31 & 2507.39 \\
df & 14 & 14 & 14 \\
$P$ & .000 & .000 & .000 \\
\hline
\end{tabular}

better in identifying useful ideas because these are not usually easy to implement by firms (Poetz and Schreier 2012). Although customer preferences under the scheme of open innovation can overcome some resistance to change, there is still some biases in managerial decision-making, as it can be observed in the results obtained. As a result, companies can miss some important disruptive innovations that can be competitive advantages for the future.

In order to overcome these problems, it is important for companies performing open innovation schemes to introduce some monitoring activities about the decision-making processes, able to detect some biases. At this point, this paper offers a methodological contribution by using some methods for data collection in social media. The main advantage of the proposed method is that it can work with the whole data set instead of a sample, as information about all previous posted innovation can be easily accessed using computer-based tools. The comparison between customer and company preferences can detect areas of innovations not considered previously. Moreover, customer preferences can also be analysed through the different categories in which 


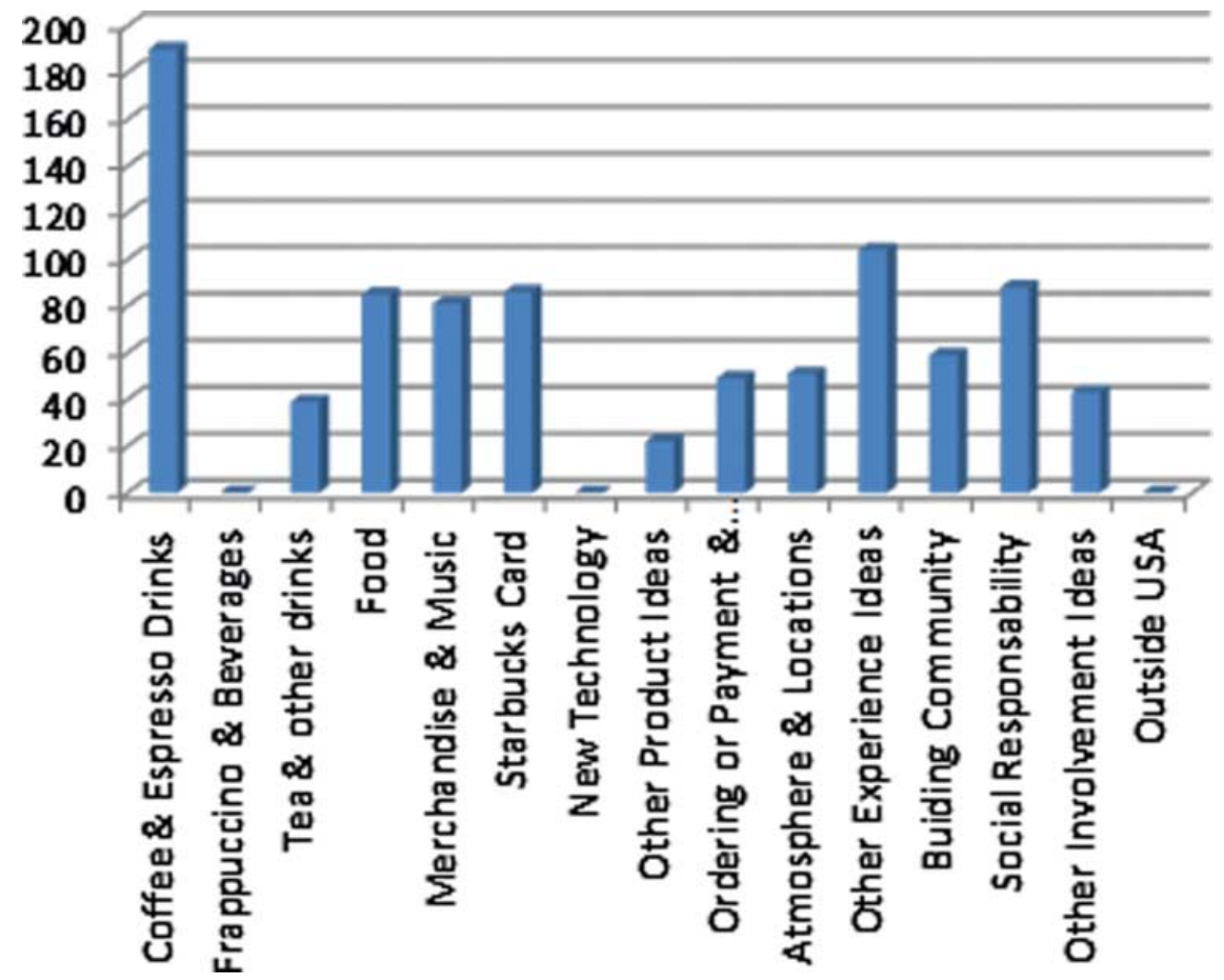

Figure 4. Distribution of ideas in action per category.

they can post innovations. The selection of the categories is made up by the company, and it is important to decide which areas are available, since they guide in some way the customers' contributions.

The results obtained in this study show that customers tend to focus on the core activity of the company, coffee and food, and on those ideas that report more comfort and benefits, for instance, those ideas related to ordering and payment, or loyalty cards (Vargo and Lusch 2004). This means that customers value not only the final product but also the surrounding and the experience associated with them. Actually, the website distinguishes between product, experience and involvement ideas, as shown in Table 1. As a difference, the company is focused on the distinctive features associated with the brand image. According to Cretu and Brodie (2007), the brand's image has a more specific influence on the customers' perceptions of product and service quality. It is worth mentioning that the New Technology group of ideas receive many comments, but they are evaluated with low scores. This point can be explaining because those authors posting technological ideas are more sensitive to intellectual property issues and they can be resilient to make open their contributions without any kind of rewards, as may happen in other open innovation schemes. Open innovation communities like My Starbucks Idea can only provide intangible rewards such as community cooperation, learning new ideas and having entertainment (Antikainen, Mäkipää, and Ahonen 2010). Additionally, technological innovations require high investments that are not usually considered by hospitality companies. 
Several limitations and future research works can be addressed. The paper is limited to a case study. Therefore, the work could be extended by analysing some other open innovation communities and confirming if managerial decision-making is also biased in the same way. Another limitation is that the paper is only focused on the activity of customers when posting, commenting or scoring innovations. However, the content of contributions was not considered. Research methods coming from Social Media analytics have been used for data extraction. But some other research methods could be applied to go further in the analysis of open innovation communities. For instance, the content of posted contributions could be processed using semantic analysis techniques to obtain the main topics (Martínez-Torres et al. 2013), both from the side of customers and from the side of the company. In this way, the study would not be limited to the categories or tags selected by the company, as it is the case in this work. Moreover, this analysis could also be used to check whether the tags selected by the company actually fit the real contributions of customers or they are actually constraining their creativity. Finally, the study could be extended to other types of open innovation schemes with a stronger link between the company and contributors, for instance, through rewards or compensation to the participants.

\section{Conclusions and implications}

This paper is focused on the open innovation community of Starbucks, which is based on sharing ideas through a specific website run by this company. The aim of the paper is to distinguish between users and company preferences when deciding about the most interesting shared ideas. Both of them are logically focused on the main product of the company: coffee and espresso drinks. However, users tend to promote those ideas that report more comfort and personal benefits, while the company is more focused on those issues related to the brand image, like the beliefs and feeling associated with the experience of taking a coffee.

\section{Disclosure statement}

No potential conflict of interest was reported by the authors.

\section{Funding}

This work was supported by the Consejería de Economía, Innovación, Ciencia y Empleo under the Research Project with reference P12-SEJ-328 and by the Programa Estatal de Investigación, Desarrollo e Inovación Orientada a los Retos de la Sociedad under the Research Project with reference ECO2013-43856-R.

\section{Notes on contributors}

María del Rocío Martínez-Torres is an Associate Professor in Management and Business Administration at Business Administration and Marketing Department, University of Seville. Her main research interests include Intellectual Capital and Knowledge Management, and Social Network Analysis. She has co-authored articles in many leading academic and professional journals, including: Information and Management; IEEE Transactions on Education; Computers \& Education; and Behaviour and Information Technology.

F. Rodriguez-Piñero is an Assistant Professor at Business Administration and Marketing Department, University of Seville. His research involves e-business, information systems and development of interactive software for instruction in business administration.

Sergio L. Toral is an Associate Professor in Digital Electronic Systems at the Department of Electronic Engineering, 
University of Seville. His main research interests include Open Source Software projects, Open Innovation and Social Network Analysis.

\section{ORCID}

María del Rocío Martínez-Torres (D) http://orcid.org/0000-0002-1640-0020

Sergio L. Toral (D) http://orcid.org/0000-0003-2612-0388

\section{References}

Alam, I. 2002. “An Exploratory Investigation of user Involvement in New Service Development.” Academy of Marketing Science 30 (3): 250-261.

Alam, I. 2006. "Removing the Fuzziness from the Fuzzy Front-End of Service Innovations Through Customer Interactions." Industrial Marketing Management 35 (4): 468-480.

Anderl, E., I. Becker, F. V. Wangenheim, and J. Schumann. 2013. "Mapping the Customer Journey: A Graph based Framework for Online Attribution Modeling." Social Science Research Network: http://ssrn.com/abstract = 2343077.

Antikainen, M., M. Mäkipää, and M. Ahonen. 2010. "Motivating and Supporting Collaboration in Open Innovation." European Journal of Innovation Management 13 (1): 100-119.

Arenas-Marquez, F. J., M. R. Martinez-Torres, and S. L. Toral. 2014. "Electronic Word of Mouth Communities from the Perspective of Social Network Analysis.” Technology Analysis \& Strategic Management 26 (8): 927-942.

Bajic, D., and K. Lyons. 2011. "Leveraging Social Media to Gather User Feedback for Software Development." In Proceedings of the 2nd International Workshop on Web 2.0 for Software Engineering, Web2SE, 1-6. New York: ACM.

Bayus, B. L. 2013. "Crowdsourcing New Product Ideas over Time: An Analysis of the Dell IdeaStorm Community." Management Science 59 (1): 226-244.

Bonabeau, E. 2009. "Decisions 2.0: The Power of Collective Intelligence.” MIT Sloan Management Review 50 (2): 45-52.

Brabham, D. C. 2013. Crowdsourcing. Boston, MA: MIT Press.

Chang, R. M., R. J. Kauffman, and Y. Kwon. 2014. "Understanding the Paradigm Shift to Computational Social Science in the Presence of Big Data." Decision Support Systems 63: 67-80.

Chiu, C.-M., T.-P. Liang, and E. Turban. 2014. "What Can Crowdsourcing Do for Decision Support?" Decision Support Systems 65: 40-49.

Chresbrough, H. 2003. Open Innovation: The New Imperative for Creating and Profiting from Technology. Boston, MA: Harvard Business School Press.

Cooper, R. G., and E. J. Kleinschmidt. 1994. "Determinants of Timeliness in Product Development." Journal of Product Innovation Management 11 (5): 381-96.

Cretu, A. E., and R. J. Brodie. 2007. "The Influence of Brand Image and Company Reputation Where Manufacturers Market to Small Firms: A Customer Value Perspective.” Industrial Marketing Management 36 (2): 230-240.

Dahlander, L., and H. Piezunka. 2014. "Open to Suggestions: How Organizations Elicit Suggestions Through Proactive and Reactive Attention.” Research Policy 43 (5): 812-827.

Füller, J., K. Möslein, K. Hutter, and J. Haller. 2010. "Evaluation Games - How to Make the Crowd Your Jury." 40th Annual Conference: Informatik 2010: Service Science- Neue Perspektiven für die Informatik, Gesellschaft für Informatik, Leipzig, Germany, 955-960.

Gassmann, O., E. Enkel, and H. W. Chesbrough. 2010. “The Future of Open Innovation.” R\&D Management 40 (3): 213-221.

Grönroos, C. 2000. Service Management and Marketing - A Customer Relationship Management Approach. Chichester: John Wiley \& Sons.

Harland, P. E., and A. M. Nienaber. 2014. "Solving the Matchmaking Dilemma Between Companies and External Idea Contributors." Technology Analysis \& Strategic Management 26 (6): 639-653.

Hekkert, M. P., and S. O. Negro. 2009. "Functions of Innovation Systems as a Framework to Understand Sustainable Technological Change: Empirical Evidence for Earlier Claims.” Technological Forecasting and Social Change 76 (4): 584-594.

Holzmann, T., K. Sailer, and B. Galbraith. 2014. "Matchmaking for Open Innovation - Theoretical Perspectives Based on Interaction, Rather than Transaction.” Technology Analysis \& Strategic Management 26 (6): 595-599. 
Huff, A., K. Moslein, and R. Reichwald. 2013. "The Future of Crowdsourcing: From Idea Contests to MASSive Ideation Leading Open Innovation.” In Leading Open Innovation, 241-261. Boston, MA: MIT Press.

Huizingh, E. K. R. E. 2011. "Open Innovation: State of the Art and Future Perspectives.” Technovation 31 (1): $2-9$.

Kim, S., and S. Miranda. 2011. "Seeds of Change: Substance and Influence in Brand Communities." Thirty Second International Conference on Information Systems, Shanghai, paper 30.

Kozinets, R. V. 2002. "The Field Behind the Screen: Using Netnography for Marketing Research in Online Communities." Journal of Marketing Research 39 (1): 61-72.

Kuusisto, A. 2008. "Customer Roles in Business Service Production - Implications for Involving the Customer in Service Innovation." In Customer Role in Service Production and Innovation - Looking for Directions for Future Research, edited by A. Kuusisto and S. Päällysaho. Lappeenranta University of Technology, Faculty of Technology Management Research, report 195.

Li, Q., J. Wang, Y. P. Chen, and Z. Lin. 2010. "User Comments for News Recommendation in Forum-Based Social Media." Information Sciences 180 (24): 4929-4939.

Mahr, D., and A. Lievens. 2012. "Virtual Lead User Communities: Drivers of Knowledge Creation for Innovation." Research Policy 41 (1): 167-177.

Martinez-Torres, M. R. 2013. "Application of Evolutionary Computation Techniques for the Identification of Innovators in Open Innovation Communities.” Expert Systems with Applications 40 (7): 2503-2510.

Martinez-Torres, M. R. 2014a. "Analysis of Open Innovation Communities from the Perspective of Social Network Analysis." Technology Analysis \& Strategic Management 26 (4): 435-451.

Martinez-Torres, M. R. 2014b. "Analysis of Activity in Open Source Communities Using Social Network Analysis Techniques.” Asian Journal of Technology Innovation 22 (1): 114-130.

Martinez-Torres, M. R. 2015. "Content Analysis of Open Innovation Communities Using Latent Semantic Indexing." Technology Analysis \& Strategic Management. doi:10.1080/09537325.2015.1020056.

Martínez-Torres, M. R., S. L. Toral, F. Barrero, and D. Gregor. 2013. "A Text Categorisation Tool for Open Source Communities Based on Semantic Analysis." Behaviour \& Information Technology 32 (6): 532-544.

Poetz, M. K., and M. Schreier. 2012. "The Value of Crowdsourcing: Can Users Really Compete with Professionals in Generating New Product Ideas?” Journal of Product Innovation Management 29 (2): 245-256.

Sigala, M. 2012. "Social Networks and Customer Involvement in New Service Development (NSD)." International Journal of Contemporary Hospitality Management 24 (7): 966-990.

Strauss, A., and J. M. Corbin. 1998. Basics of Qualitative Research: Techniques and Procedures for Developing Grounded Theory. Thousand Oaks, CA: Sage.

Tepeci, M. 1999. "Increasing Brand Loyalty in the Hospitality Industry." International Journal of Contemporary Hospitality Management 11 (5): 223-230.

Toral, S. L., M. R. Martínez-Torres, and F. Barrero. 2009. "Modelling Mailing List Behaviour in Open Source Projects: The Case of ARM Embedded Linux." Journal of Universal Computer Science 15 (3): 648-664.

Toral, S., M. R. Martinez-Torres, and P. Di Gangi. 2011. "User Innovations Through Online Communities from the Perspective of Social Network Analysis." In The First International Conference on Advanced Collaborative Networks, Systems and Applications, COLLA, 40-45. Red Hook: IARIA.

Vargo, S. L., and R. F. Lusch. 2004. "Evolving to a New Dominant Logic for Marketing.” Journal of Marketing 68: $1-17$.

Wu, W. C. 2008. The Study of Influence of Brand Equity, Customer Value, Customer Satisfactions and Customer Loyalty - A Case Study of Wretch. Taiwan: Department of Communications Management, Ming Chuan University.

Youtie, J., D. Hicks, P. Shapira, and T. Horsley. 2012. "Pathways from Discovery to Commercialisation: Using Web Sources to Track Small and Medium-Sized Enterprise Strategies in Emerging Nanotechnologies." Technology Analysis \& Strategic Management 24 (10): 981-995. 